\title{
A ESCRITA JAPONESA
}

\section{Tae Suzuki}

Com exceção da transcrição em letras romanas, os japoneses dispõem de três espécies de grafia - uma ideográfica (kanji) e duas silábicas (hiragana e katakana) - para expressar sua língua, todas originárias da escrita ideográfica chinesa. $O$ registro mais antigo da escrita chinesa remonta à época da dinastia Yin (por volta do século XIV A.C.), constituído de pictogramas gravados em cascos de tartaruga ou em ossos de animais, supondo-se que tenham sido utilizados para adivinhações e sortilégios.

Tendo surgido sob a forma de pictogramas, os símbolos gráficos foram usados também em metais e pedras até que por volta do século III A.C., começam a surgir as formas estilizadas, as formas gráficas propriamente ditas. Os ideogramas (kanji) podem ser classificados, segundo sua composição, em:

1. shôkei, literalmente "figura" - são os ideogramas que representam pictoricamente objetos, elementos da natureza. Ex.: $\iint f$ "rio" (川); “ "montanha" (山); $\odot$ “sol" (日) ). Apesar de constituírem a forma originária de criação de ideogramas, seu número é reduzido, correspondendo a cerca de $3 \%$ do total de ideogramas hoje existentes.

2. shiji, literalmente "indicação" - são os ideogramas que representam idéias abstratas por meio de figuras simbólicas ou por acréscimo de pontos ou traços a ideogramas shôkei. Ex.: - "em cima" 
( 上); T“em baixo" (下); 本 “base”, originário de $\Psi$ “árvore" (木) cortado na base por um traço. Em número bastante reduzido, correspondem a cerca de $0,5 \%$ do total de ideogramas atualmente usados.

3. kaii - com cerca de $3 \%$ do total de ideogramas, são aqueles que

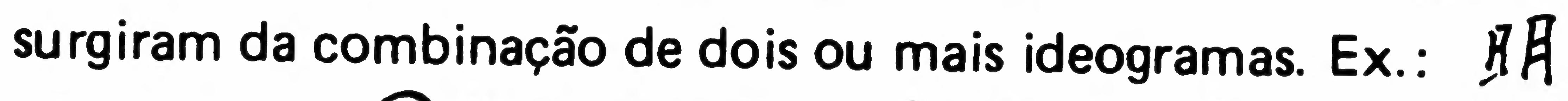
formado de $\odot$ "sol" (日) e $A$ "lua" (月) para significar "claridade"; 萧 "leste", formado de $\odot$ "sol" (日) que surge atrás da "árvore" $\Psi$ (木).

4. Keisei, literalmente "conceito e som" - são os ideogramas que nasceram da combinação de um ideograma que lhe dá a leitura e de outro que lhe dá o conceito. Ex.: na seqüência dos ideogramas 梅桃 e 枝 temos, respectivamente, “ameixa", pèssego" e "galho"; o ideograma $木$ "árvore" à esquerda, indica que os ideogramas têm relação com árvore como têm a ameixa, o pêssego e o galho; os ideogramas 每兆 e 支 (à direita), pronunciados bai, tô e shi dão a leitura a 梅 (bai “ameixa"), 桃 (tô "pêssego") e 枝 (shi "galho") A maioria dos ideogramas atuais são de formação keisei e correspondem a cerca de $90 \%$ do total.

Posteriomente, foram criados novos ideogramas por associação ou adaptação dos já existentes:

1. tenchû - são os ideogramas que sofreram uma modificação no seu conceito origirário e foram adaptados a idćias aproximadas (cerca de 1,5\%). Ex.: 泉， originariamente gaku "música", passa a ser lido raku "agradável", por implicar que música é agradável de ser ouvida.

2. kasha(ku), literalmente "empréstimo" - são os ideogramas $(2,4 \%)$ que surgiram da adaptação de símbolos ou letras a termos homófonos, sem nenhuma relação com conceitos ou idéias. Ex.: 而, originariamente $j i$ "bigode", usado para o conetivo $j i$ " $\mathrm{e}$ "; 來, rai "trigo", usado para o verbo rai "vir" Processo muito 
utilizado para escrever nomes próprios estrangeiros, encontramos, por exemplo, em Gishi "História de Wei", no capítulo Wajinden "Sobre o povo de Wa" do volume Sangokushi "História de três povos" (século III, o nome de Himiko e o povo de Yamato, do qual era soberana, grafados邪馬台e 重弥呼

hi mi ko ya ma to

E difícil precisar a época em que os japoneses tiveram o primeiro contato com a escrita chinesa, ou em que passaram a vê-la e compreendê-la como símbolos gráficos até poderem utilizá-los para expressar seus próprios pensamentos, idéias ou sentimentos. Apenas algumas hipóteses podem ser levantadas a partir de dados arqueológicos ou referências em tex tos chineses.

A inscrição em uma moeda encontrada em escavações feitas em um túmulo da era Yayoi (séc. III A.C. - séc. III D.C.) constitui o registro mais antigo da escrita ideográfica no Japão. Embora não se possa determinar a época de sua entrada no Japão, a moeda foi cunhada durante o império Wan Mao (do ano 8 a 23 de nossa era).

Livros históricos chineses trazem referências ao Japão do século 1 D.C.. Kanjo "História de Han", escrito no século I, descreve o país de Wa, nome por que era conhecido, como um país constituído por mais de uma centena de pequenos povos. $O$ Japão ainda não atingira o estágio de estado unificado, de modo que os contatos eram estabelecidos com nações tribais que mantinham relações regulares com a China através de sua colônia fundada na Coréia. Os representantes dessas nações recebiam sinetes oficiais do império chinês em sinal de vassalagem, onde se viam gravados ideogramas. $O$ mais antigo de que se tem notícia data do ano 57, conforme citação em Gokanjo "História de Han posterior" (séc. V), descoberto por acaso em 1784 na Il ha Shika, ao norte de Kyûshû.

Em vista desses fatos, presume-se que foi durante o império Han que os japoneses tomaram contato com a escrita ideográfica chinesa, embora nem sempre tenham discernido, no princípio, que se tratavam de sinais gráficos. Reproduções posteriores em espelhos de bronze apresentam as letras ao contrário ou com suas partes invertidas.

A partir dos séculos IV-V, assistimos à entrada em massa da cultura chinesa ao Japão, via Coréia, levada pelas mãos de emissários oficiais chineses, bem como pelas de artífices e letrados que atravessaram - Mar do Japão para se instalarem no arquipélago. Não menor foi o papel desempenhado por japoneses que, em sentido inverso, atravessaram o mar e trouxeram de volta a cultura chinesa para propagá-la em 
suas terras. Embora restritas a determinados grupos de pessoas, as letras chinesas tomam corpo no Japão e começam as primeiras produções de textos pelos japoneses.

O caráter fonético e semântico dos ideogramas, em sua maioria, dificulta sua adaptação para línguas estrangeiras que, como a japonesa, apresentam uma estrutura sintática diversa daquela da língua chinesa. A necessidade de apreensão da leitura e do significado dos kanji fez com que os primeiros textos produzidos no Japão não passassem de textos chineses (kanbun) elaborados por japoneses que aprenderam e assimilaram a nova língua.

Os registros mais antigos de kanbun datam de meados do século $\mathrm{V}$, quando o Japão já se constituíra um estado unificado em torno da corte de Yamato. São as inscrições em uma espada e em um espelho de bronze, ambos com antropônimos gravados em ideogramas adaptados foneticamente (kasha). Por essa época, foi grande a contribuição de chineses e coreanos radicados no Japão para a propagação da escrita ideográfica, muitos dos quais eram requisitados pela corte para a elaboração de textos oficiais. Por ou tro lado, aumenta consideravelmente o número de japoneses que assimilaram e usavam a escrita chinesa.

Com o tempo, os textos em chinês (kanbun) produzidos dentro e fora do Japão passam a ser traduzidos pelos letrados da época, em um estilo próprio denominado kanbunkundoku, literalmente "leitura de textos chineses em japonês" Os ideogramas anteriormente usados apenas em kanbun passam a ser empregados em textos sintaticamente japoneses. Essa passagem, porém, não é uniforme. Além da adaptação fonética de ideogramas a nomes próprios, os ideogramas são adaptados a vocábulos japoneses aproveitando-se apenas sua leitura e ignorando seu componente semântico. Assim, por exemplo, para expressar yama "montanha", são empregados os ideogramas 夜 (ya "noite") e 麻 (ma "linho"), ambos sem nenhuma relação, aproximada sequer, com "montanha" Surgem, assim, os magana, símbolos gráficos que são ideogramas na forma, mas usados apenas foneticamente para expressar termos japoneses ou elementos gramaticais inexistentes na lingua chinesa.

Se os mangana fixaram apenas o lado fonético dos ideogramas originais, por outro lado, os mesmos sofrem uma adaptação semântica a termos japoneses de mesmo significado e passam a ser lidos em japonês. O kanji. 男 "homem", por exemplo, além das leituras dan e nan (leitura kan e leitura go, respectivamente, e que veremos mais adiante) é lido otoko que significa "homem" em japonês. 
Os ideogramas eram empregados ora foneticamente, ora semanticamente, e, mesmo os foneticamente utilizados, não se limitavam a uma determinada letra para expressar um mesmo som; os mais variados ideogramas homófonos serviam para grafar um mesmo som. Mas a partir do século VII, a escrita ideográfica se afasta de suas características chinesas para se. tornar cada vez mais japonesa. Os primeiros livros de história (Kojiki, 712 e Nihonshoki, 720) são ainda escritos em kanbun "texto chinês" com exceção de canções populares e algumas expressões que os compiladores encontravam dificuldade em traduzir, mas, a primeira coletânea de poemas Man'yôshû (tida como compilada por volta de 760) já é escrita em wabun "texto japonês"

Por essa época, limita-se o número de magana para grafar os sons da língua japonesa que são silábicos. Embora ainda não se tenha restringido a um único ideograma, cada sílaba passa a ter determinados ideogramas para ser expressa, dando origem ao que posteriormente foi denominado man'yógana em razão do seu uso em larga escala na obra citada. Por exemplo: para o som a havia os ideogramas 阿安

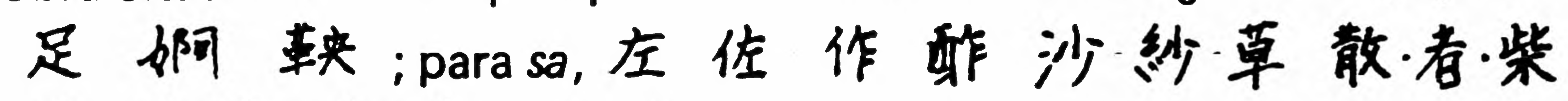

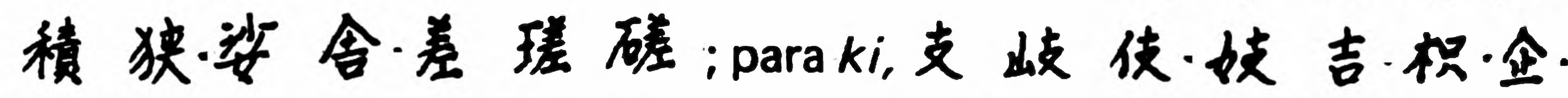
咅寸来杵·考䃼䃼

A título de exemplo, transcrevemos o poema n? 15, vol. I de Man'yôshû, citado por Komatsu (p. 36), onde determinados ideogramas são utilizados foneticamente e ou tros, semanticamente.:

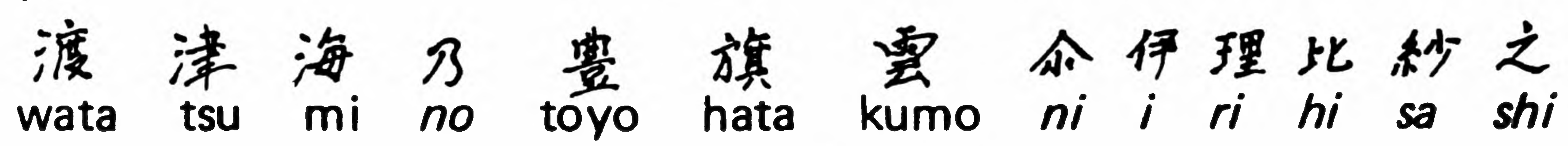

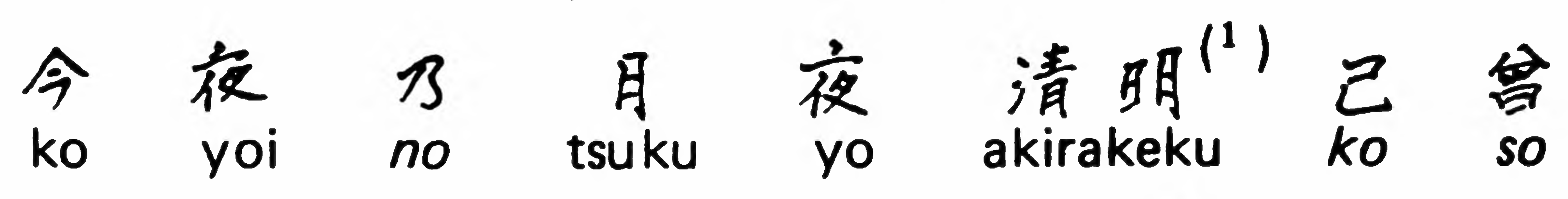

(1) Há outras interpretações para a leitura de 清明. onde,

1. as formas grifadas constituem a leitura chinesa (on) de ideogramas adaptados às partículas no, ni e koso e ao verbo irihisashi do japonês;

2. as formas sem grifo correspondem à leitura kun, isto é, à adaptação de ideogramas a termos japoneses com mesmo significado contido nos ideogramas originais. 
Foram necessários vários séculos até a escrita ideográfica se prestar a expressar a língua japonesa desde que entrou no Japão sob a forma de inscrições em objetos de metal, inicialmente, e depois, sob a forma de cânones do budismo, de textos de filosofia, direito, astronomia e demais ciências. Tendo sido assimilada por homens da nobreza, foi por suas mãos reproduzida em preceitos legais, ordens imperiais, comunicados oficiais, escritos em estilo chinês. Com o tempo, os ideogramas vão sendo adaptados à língua japonesa até poderem expressar o espírito japonês, como ocorreu com os poemas do séc. VIII.

Duas outras formas de grafia se desenvolveram a partir da escrita ideográfica que se consagrara como escrita japonesa. A primeira delas surgiu de abreviações de ideogramas, processo este que já existia na China e na Coréia, utilizando partes de ideogramas.

No Japão, entretanto, os bonzos desenvolveram dois métodos diferentes de abreviar ou de simplificar ideogramas. Um elemento de capital importância na difusão da escrita ideográfica foram as sutras do budismo que eram ensinadas nas escolas instaladas nos templos ergu idos em grande número a partir do século $\mathrm{V}$. Para auxiliar na leitura das sutras escritas em kanbun, os bonzos aprendizes se serviam de duas formas de notação.

A primeira consistia de pontos colocados nos ideogramas, denominados kunten que, conforme a posição, representavam as particulas $e$ flexões verbais do japonês inexistentes na língua chinesa e, posteriormente, foram usados para simbolizar determinados substantivos, predicativos $^{2}$ e expressões de tratamento. Esse processo é muito utilizado nos textos do séc. VIII-IX, época de florescimento das letras chinesas, variando de indivíduo a indivíduo e depois, de escola a escola. As diferenças de notação entre bonzos de uma mesma escola fazem supor que códigos individuais foram sendo propagados e unificados por escola.

"Predicativos" é o nome que demos a yógen que compreende dôshi "verbos" e keivôshi, comumente traduzidos por "adjetivos"; estes, porém, não são adjetivos no sentido exato do termo porque, conquanto signifiquem qualidade ou estado, têm uma força predicativa como em hana wa $A K A /$ "a flor E VERMELHA" Só temos a função adjetiva de keiyôshi quando ele precede o substantivo:akai hana "flor vermelha" 
Paralelamente, desenvolveu-se o processo de abreviar ideogramas utilizando partes do ideograma originário (比巴 de 琵琶, biwa "cítara") ou partes de ideogramas diferentes conjugadas em uma única forma (茾 de 蓄薩，bosatu “bodhisatva"; 金 de 金则，kongó "diamante" Concomitantemente empregadas com os kunten, suas formas que também variavam de indivíduo a indivíduo, são unificadas por escolas e acabam tomando o lugar dos kunten. As formas muito variadas e numerosas no início vão se restringindo até dar origem aos katakana por volta do século XI, época em que o uso de katakana foi bastante difundido entre estudiosos, principalmente da poética, que utilizavam em notas de poemas, e entre literatos, cujas obras eram escritas em estilo misto de ideogramas e katakana ou somente em katakana. Apresentamos, a seguir, alguns katakana atualmente usados e

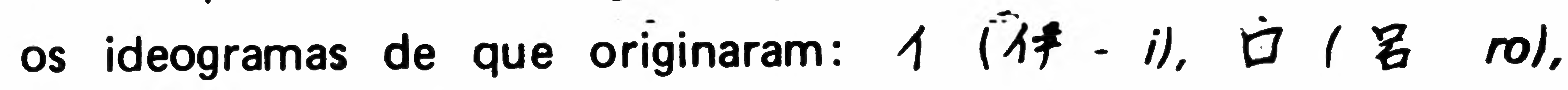
(to ka), $卜$ ( 正-to).

A outra forma de grafia originou-se do estilo de caligrafia denominado sôshotai, a forma cursiva ou corrida de man'yôgana. Sôshotai é largamente difundido no início da era Hei'an, época em que as mulheres têm acesso às letras. $E$ é pelas mãos das damas da corte que as formas já cursivas de ideogramas se tornam cada vez mais estilizadas, dando origem no século $X I$, ao que posteriormente foi denomi-

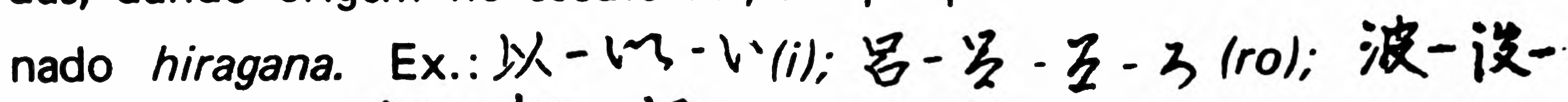
诘一l (ha); イニーにニーに (ni).

E assim, as duas formas de grafia propriamente japonesa, criadas a partir de ideogramas, se consolidam quase à mesma época, constituindo com kanji, as formas de grafia atualmente utilizadas na língua japonesa. Hiragana e katakana são grafias silábicas, acompanhando os sons da língua japonesa que são abertos. Em princípio, kanji é usado para grafar termos conceituais, katakana para nomes estrangeiros e hiragana, para os componentes gramaticais próprios da língua japonesa.

Cumpre notar que os ideogramas passaram por várias transformações no correr dos séculos e, não só sofreram as modificações que, como vimos, originaram os hiragana e katakana, como também, enquanto ideogramas, tomaram formas diferentes dos que são atualmente empregados na China, além de terem sido criados novos símbolos no Japão (kokuji, literalmente "letras nacionais"), principalmente pelo processo kaii.

Pelas adaptações por que passou o kanji, ele possui dois tipos de leitura: a leitura on que representa o som adaptado à fonética japonesa 
do ideograma originário na China, e a leitura kun que representa o som do termo japonês correspondente ao conceito contido no ideograma chinês e ao qual foi adaptado. São as duas leituras que fixaram, uma, o aspecto fonético do ideograma e outra, o seu aspecto semântico. Há, no entanto, várias leituras on "leitura chinesa" ou "leitura fonética", conforme a época de entrada da cultura chinesa ao Japão, procedente de diferentes regiões onde se localizavam os impérios então dominantes. As mais comuns são a leitura goon e kan'on, correspondendo respectivamente, à pronúncia sulina e à nortista. Go é o nome por que os japoneses denominam a cultura que dominava ao sul da China à época da primeira leva de entrada da cultura chinesa ao Japão (séc. I a séc. VII), embora Go (Wu, em chinês) não tenha sido o único império dessa fase. A leitura kan'on corresponde, grosso modo, à pronúncia do chinês que entrou no Japão depois do século VII, nome tomado do império Kan (Han, em chinês) que dominou a China do século III A.C. ao século III D.C. e pelo qual os japoneses denominam a China em geral. Assim, por exemplo, 色 lê-se iro (kun), shiki (goon), shoku (kan'on); 正 lè-se tadashii (kun), shô (goon), sei (kan'on).

Cabe citar ainda, a transliteração românica da língua japonesa, cujo documento mais antigo é a tradução do Novo Testamento (Atos dos Apóstolos) de 1591, feita por jesuítas portugueses que chegaram ao Japão no século XVI para propagar a religião cristã. Dentre as várias formas de transliteração que surgiram depois que o Japão abandonou sua política de isolacionismo (séc. $X V|I-X| X$ ), a mais utilizada é o sistema Hepburn, criado pelo médico e padre americano James Curtis Hepburn nos meados do século passado e re-elaborado pela Associação de Transliteração (Rômajikai) em 1885. Esse sistema segue em linhas gerais a fonética inglesa com $h$ aspirado, $\left.c h(t)), j\left(d_{z}\right), s h()\right), g e, g i$ (ge, gi); $w(w)$.

Não foram poucas as discussões soḅre a conveniência ou não de romanizar a língua japonesa e extinguir as demais formas de escrita, mas a existência de muitos termos homófonos cujos significados são apreensíveis pelos ideogramas com que são grafados, é o argumento pelo qual a língua japonesa continua sendo escrita em kanji, katakana e kiragana, e em rômaji "letras romanas", quando necessário. 


\section{BIBLIOGRAFIA}

HAYASHI, C.

(1977) Nihon-niokeru Kanji "O Ideograma no Japão" In Iwanami Kôza Nihongo v.8 - Moji (Tóquio, Iwanami) - pp. 159 - 248.

KOMATSU, S.

(1972) Kana - sono Seiritsu-to Hensen "Kana - sua formação e sua evolução" (Tóquio, Iwanami)

KUSAKABE, $F$

(1977) Nihon-no Rômaji "A escrita romana do japonés" In Iwanami Kôza citado, pp. 341 - 383.

OTSUBO, $\mathrm{H}$.

(1977) Katakana - Hiragana (mesmo título em português). In Iwanami Kôza citado, pp. 249 - 299.

TSURU, $H$.

(1977) Man'yôgana (mesmo título em portuguès). In Iwanami Kôza citado pp. $209-247$. 